\title{
ERRATUM
}

\section{IMPLICIT LEARNING IN SLA AND THE ISSUE OF INTERNAL VALIDITY-ERRATUM}

\section{A Response to Leung and Williams's (2011) "The Implicit Learning of Mappings Between Forms and Contextually Derived Meanings"}

Ronald P. Leow and Mike Hama

doi:10.1017/S027226311300003X, Published by Cambridge University Press, 29 May 2013

The first name of the second author was misspelled in the original article. The correct full name of the second author is Mika Hama.

\section{REFERENCE}

Leow, R. P., \& Hama, M. (2013). Implicit learning in SLA and the issue of internal validity: A response to Leung and Williams's (2011) "The implicit learning of mappings between forms and contextually derived meanings." Studies in Second Language Acquisition, doi: 10.1017/S027226311300003X. 